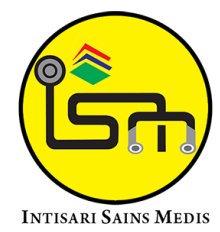

\section{Situasi analisis pelayanan kesehatan mata di Provinsi Bali, Indonesia}

Published by Intisari Sains Medis
Anak Agung Ayu Githasari Dewi ${ }^{1 *}$, Ni Made Ari Suryathi', Ni Made Suryanadi', I Made Agus Kusumadjaja', I Wayan Eka Sutyawan', Anak Agung Mas Putrawati Triningrat", I Wayan Gede Jayanegara ${ }^{1}$
'Departemen/KSM IImu Kesehatan Mata, Fakultas Kedokteran, Universitas Udayana-RSUP Sanglah Denpasar, Bali, Indonesia;

\section{*Korespondensi:}

Anak Agung Ayu Githasari Dewi;

Departemen/KSM IImu Kesehatan Mata, Fakultas Kedokteran, Universitas Udayana-RSUP Sanglah Denpasar, Bali, Indonesia;

ayu.githasaridewi@gmail.com

Diterima: 05-08-2021

Disetujui: 18-12-2021

Diterbitkan: 29-12-2021

\section{ABSTRACT}

Introduction: The prevalence of blindness in Bali based on Rapid Assessment of Avoidable Blindness (RAAB) survey in 2015 was $2 \%$. This prevalence rate is still high according to WHO guidelines. Bali has challenges in providing eye care services. The aim of this study was to report situational analysis of the eye care in Bali.

Method: This is a descriptive study with quantitative and qualitative approach. Data collection was carried out through interviews and questionnaires targeting respective stakeholders involved in the eye care services in Bali.

Result: Bali consists of 9 districts with total 4,337 million people. Eye care in Bali consist of 43 hospitals, 120 primary health care (Puskesmas), 73 general ophthalmologist and subspecialists, 18 trained

opthalmic nurses, and 12 refractionist. Bali has mobile eye care unit covering remotes area and a NonGovernment Organization (NGO) actively contributing in community eye care service. Total number of cataract surgery in 2019 was 8.225 eyes with cataract surgical rate (CSR) was 1.896. Komite Mata Daerah (Komatda) dan health insurance for eye service and eye surgery is a form of support from the government.

Conclusion: The implementation of eye care services in Bali is yet under evaluation. Things needed to consider to improve eye care services including providing better distribution of ophthalmologist to districts, and empowering voluntary local manpower as village health workers / cadres through regularly organized training. Education on blindness and preventable visual disturbances also must be carried out regularly.

Keywords: Bali, situational analysis, eye care services, cataract surgery, human resources.

Cite This Article: Dewi, A.A.A.G., Suryathi, N.M.A., Suryanadi, N.M., Kusumadjaja, I.M.A., Sutyawan, I.W.E., Triningrat, A.A.M.P., Jayanegara, I.W.G. 2021. Situasi analisis pelayanan kesehatan mata di Provinsi Bali, Indonesia. Intisari Sains Medis 12(3): 952-957. DOI: 10.15562/ism.v12i3.1104

\title{
ABSTRAK
}

Pendahuluan: Prevalensi kebutaan di Bali berdasarkan survei Rapid Assessment of Avoidable Blindness (RAAB) tahun 2015 sebesar 2\%. Angka prevalensi ini masih tinggi menurut pedoman WHO. Bali memiliki tantangan dalam memberikan pelayanan perawatan mata. Tujuan dari penelitian ini adalah untuk melaporkan analisis situasi perawatan mata di Bali.

Metode: Penelitian ini merupakan penelitian deskriptif dengan pendekatan kuantitatif dan kualitatif. Pengumpulan data dilakukan melalui wawancara dan kuesioner dengan sasaran masing-masing pemangku kepentingan yang terlibat dalam layanan perawatan mata di Bali.

Hasil: Bali terdiri dari 9 kabupaten dengan jumlah penduduk 4.337 juta jiwa. Perawatan mata di Bali terdiri dari 43 rumah sakit, 120 Puskesmas, 73 dokter spesialis mata umum dan subspesialis, 18 perawat mata terlatih, dan 12 dokter spesialis mata. Bali memiliki unit perawatan mata keliling yang mencakup daerah terpencil dan Lembaga Swadaya Masyarakat (LSM) yang aktif berkontribusi dalam layanan perawatan mata masyarakat. Jumlah operasi katarak pada tahun 2019 sebanyak 8.225 mata dengan angka bedah katarak (CSR) sebanyak 1.896. Komite Mata Daerah (Komatda) dan jaminan kesehatan untuk pelayanan mata dan operasi mata merupakan bentuk dukungan dari pemerintah.

Simpulan: Pelaksanaan pelayanan kesehatan mata di Bali masih dalam tahap evaluasi. Hal-hal yang perlu diperhatikan untuk meningkatkan pelayanan kesehatan mata antara lain penyediaan dokter spesialis mata yang lebih merata ke kabupaten, dan pemberdayaan tenaga sukarelawan lokal sebagai kader/petugas kesehatan desa melalui pelatihan yang diselenggarakan secara rutin. Edukasi tentang 
kebutaan dan gangguan penglihatan yang dapat dicegah juga harus dilakukan secara berkala.

Kata kunci: Bali, analisis situasi, pelayanan kesehatan mata, operasi katarak, sumber daya manusia. Sitasi Artikel ini: Dewi, A.A.A.G., Suryathi, N.M.A., Suryanadi, N.M., Kusumadjaja, I.M.A., Sutyawan, I.W.E., Triningrat, A.A.M.P., Jayanegara, I.W.G. 2021. Situasi analisis pelayanan kesehatan mata di Provinsi Bali, Indonesia. Intisari Sains Medis 12(3): 952-957. D0I: 10.15562/ism.v12i3.1104

\section{PENDAHULUAN}

Gangguan penglihatan dan kebutaan masih merupakan salah satu masalah kesehatan terbesar di dunia. ${ }^{1}$ Data gangguan penglihatan global terakhir yang dikumpulkan pada tahun 2015, diperkirakan terdapat 253 juta orang menderita gangguan penglihatan, dimana dari jumlah tersebut sekitar 36 juta orang menderita kebutaan dan 217 orang menderita gangguan penglihatan sedang dan berat. ${ }^{1}$ Penyebab Kebutaan terbanyak di seluruh dunia adalah katarak (39\%), gangguan refraksi (18\%), glaukoma (10\%), dan diikuti age related macular degeneration (AMD) (7\%), sikatrik kornea (4\%) dan retinopati diabetika (4\%). ${ }^{2}$

Orang dengan gangguan penglihatan di Indonesia adalah diperkirakan sebesar 6,4 juta orang. Prevalensi kebutaan di Bali berdasarkan survey Rapid Assessment of Avoidable Blindness (RAAB) tahun 2015 adalah sebesar 2\%. ${ }^{1}$ Prevalensi tersebut tergolong tinggi berdasarkan World Health Organization (WHO) dan merupakan masalah kesehatan masyarakat.

Menyikapi prevalensi kebutaan tersebut, provinsi Bali sebagai etalase Indonesia di mata dunia yang menjadi salah satu tolak ukur kesehatan mata nasional menghadapi tantangan dalam menyediakan pelayanan kesehatan mata. Analisis situasi terhadap pelayanan kesehatan mata diperlukan sebagai angkah awal untuk mengetahui situasi dan kondisi yang ada di lapangan. Tulisan ini memaparkan mengenai analisis situasional pelayanan kesehatan mata di provinsi Bali.

\section{METODE}

Penelitian ini adalah studi deskriptif dengan pendekatan metode kualitatif dan kuantitatif yang dilakukan sejak 1 September sampai dengan 30 November 2020 di Provinsi Bali. Data diambil dari wawancara yang dilakukan kepada beberapa informan diantaranya adalah pemegang program pelayanan kesehatan mata di beberapa puskesmas di provinsi Bali, dokter spesialis mata, pengurus Perhimpunan Dokter Mata Indonesia (PERDAMI) Cabang Bali, NonGovernment Organizatation (NGO) yang mendukung pelayanan kesehatan mata di provinsi Bali dan pejabat yang berwenang dari Dinas Kesehatan Provinsi. Penelusuran kepustakaan juga dilakukan untuk melengkapi kekurangan data yang tidak didapatkan.

\section{HASIL}

Provinsi Bali merupakan salah satu provinsi di Indonesia dengan luas wilayah sebesar 5.780,06 $\mathrm{km}^{2}$. Provinsi Bali terdiri dari 9 kabupaten/kota yaitu Jembrana, Tabanan, Badung, Gianyar, Klungkung, Bangli, Karangasem, Buleleng dan Kota Denpasar. Jumlah penduduk Bali pada tahun 2019 berdasarkan hasil proyeksi Badan Pusat Statistik (BPS) yang didasarkan pada hasil Sensus Penduduk tahun 2010 sebesar mencapai 4.336,9 juta jiwa, dengan jumlah populasi terbanyak yaitu di Kota Denpasar sebanyak 947,1 juta jiwa dan Kabupaten Badung sebanyak 670,2 juta jiwa. Jumlah penduduk lakilaki yaitu 2.184,1 juta jiwa dan penduduk wanita yaitu 2.152,8 juta jiwa. Jumlah penduduk yang berusia di atas 50 tahun adalah $1.009,8$ juta jiwa (23,3\%) dan penduduk usia sekolah (5-14 tahun)

\section{Tabel 1. Data sumber daya yang berhubungan dengan pelayanan Kesehatan mata di Provinsi Bali.}

\begin{tabular}{lc}
\hline Sumber daya & Jumlah \\
\hline Rumah sakit & 43 \\
Puskesmas & 120 \\
Spesialis mata & 73 \\
Perawat mahir & 18 \\
Refraksionis & 12 \\
Mobile unit & 2 \\
Non-Government Organization & 1 \\
\hline
\end{tabular}

adalah 683,1 juta jiwa $(15,6 \%)$.

Jumlah dokter mata di Bali pada akhir tahun 2019 berdasarkan data dari PERDAMI Cabang Bali adalah 68 dokter dan tersebar seluruh kabupaten/kota di provinsi Bali, kecuali di Kabupaten Jembrana. Pada akhir tahun 2020 tercatat 73 Dokter spesialis mata di Bali dan telah tersebar di 43 rumah sakit pemerintah/ swasta di seluruh kabupaten/kota termasuk Kabupaten Jembrana. Dua diantara 43 rumah sakit tersebut adalah rumah sakit khusus mata yaitu RS Mata Bali Mandara dan RS Mata Ramata. Pelayanan Kesehatan mata di rumah sakit rujukan juga dibantu oleh 18 orang perawat mahir dan 12 orang refraksionis terlatih (Tabel 1).

Jumlah Puskesmas di provinsi Bali pada akhir tahun 2019 adalah sebanyak 120 puskesmas. Setiap Puskesmas di Bali menjalankan program pelayanan kesehatan mata yang dikoordinir oleh satu orang pemegang program. Jenis pelayanan kesehatan yang dilakukan di puskesmas beragam mulai dari pemeriksaan visus, buta warna, skrining refraksi dan penyuluhan kesehatan mata.

Pemerintah Provinsi Bali telah memiliki Komite Mata Daerah (Komatda) yang dibentuk berdasarkan Surat Keputusan (SK) Gubernur sebagai salah satu upaya meningkatkan pelayanan Kesehatan mata di Bali. Pemerintah juga mengalokasikan dana untuk program 
Tabel 2. Jumlah operasi dalam dan luar gedung pada tahun 2019.

\begin{tabular}{lc}
\hline Tempat Operasi & Jumlah Operasi Katarak \\
\hline Operasi Dalam Gedung & \\
Jembrana & 563 \\
Tabanan & 261 \\
Badung & 659 \\
Gianyar & 20 \\
Klungkung & 97 \\
Bangli & 223 \\
Karangasem & 713 \\
Buleleng & 4.731 \\
Kota Denpasar & \\
Operasi Luar Gedung & 347 \\
PGPK RS Mata Bali Mandara & 611 \\
PGPK JFF & $\mathbf{8 . 2 2 5}$ \\
Total & \\
\hline
\end{tabular}

pelayanan kesehatan mata yang diambil dana Bantuan Operasional Kesehatan (BOK) dan menyediakan system asuransi Kesehatan nasional yaitu BPJS.

Provinsi Bali memiliki mobile unit untuk pelayanan kesehatan mata yang dapat menjangkau area yang memiliki kesulitan akses menuju fasilitas pelayan kesehatan. Melalui program Penanggulangan Gangguan Penglihatan dan Kebutaan (PGPK) yang dilakukan oleh RS Mata Bali Mandara Provinsi Bali bekerja sama dengan PERDAMI Bali melakukan pelayanan luar gedung di seluruh daerah di provinsi Bali. Kegiatan ini bekerja sama dengan Dinas Kesehatan Kabupaten/Kota dan Puskesmas. Kegiatan yang dilakukan berupa pemeriksaan mata dan skrining serta operasi katarak gratis dengan menggunakan bus keliling (Tabel 2).

Yayasan Kemanusiaan Indonesia (YKI) / John Fawcett Foundation (JFF) merupakan salah satu Non-Government Organization (NGO) di Bali yang turut berperan dalam pelayakan kesehatan mata di Provinsi Bali. JFF bekerjasama dengan PERDAMI Bali melakukan PGPK berupa skrining dan operasi katarak dalam bis secara gratis di berbagai wilayah di Provinsi Bali. JFF bekerja sama dengan Dinas terkait seperti Dinas Kesehatan Kabupaten dan Dinas Sosial.

\section{PEMBAHASAN}

Survey Rapid Assessment of Avoidable Blindness (RAAB) merupakan metode pengumpulan data kebutaan dan gangguan penglihatan penduduk usia 50 tahun ke atas yang direkomendasikan oleh WHO. WHO menyatakan bahwa tingkat kebutaan yang diharapkan pada suatu negara adalah kurang dari 0,5\%, sedangkan secara keseluruhan angka kebutaan berdasarkan RAAB 2014-2016 di Indonesia adalah 3.0\% Prevalensi kebutaan di Bali berdasarkan survey RAAB tahun 2015 adalah sebesar 2\% dengan penyebab terbanyak adalah katarak yaitu 77,8\%. Batas prevalensi kebutaan yang tidak menjadi masalah kesehatan masyarakat menurut standar WHO adalah $0,5 \%$, sedangkan prevalensi di atas $1 \%$ menunjukkan adanya keterlibatan masalah sosial/lintas sektor. ${ }^{3}$

Indonesia mengadopsi dari konsep Universal Eye Health membuat suatu panduan Peta Jalan Penanggulangan Gangguan Penglihatan di Indonesia Tahun 2017-2030 dalam rangka mewujudkan Vision 2020, The Right to Sight dan Universal Eye Health.,5 Sistem kesehatan mata nasional diperankan dan diperkuat oleh 6 Building Blocks, yaitu : Tata Kelola Pemerintah (Govermance), Sumber Daya Manusia (Human Resources), Sistem Keuangan (Health Financing), Obat-obatan dan Teknologi Kesehatan (Consumables and Technology) dan Akses Layanan Kesehatan (Service Delivery), ditambah dengan Kemitraan (Partnerships). Melalui 6 Building Block dari sistem kesehatan ini, diharapkan tujuan pelayanan kesehatan untuk meningkatkan status kesehatan masyarakat khususnya di bidang kesehatan mata dapat dicapai melalui struktur program kesehatan terintegrasi dan terstruktur. ${ }^{3}$

Tata Kelola pemerintah penting dalam sistem kesehatan dengan tujuan agar berbagai kebijakan dan aturan pemerintah pusat dan daerah dalam mendorong keberhasilan program dan kegitan terkait kesehatan mata di semua tingkatan pemerintahan, terutama di tingkat kebupaten kota dapat dilaksanakan secara efektif. Indikator dari tata kelola pemerintah ini adalah dengan terbentuknya koordinator Penanggunakan Gangguan Penglihatan di Tingkat Provinsi. Komite Mata Nasional Penanggulangan Gangguan Penglihatan dan Kebutaan (Komatnas PGPK) diaktifkan kembali pada tahun 2015. ${ }^{6}$ Bali merupakan salah satu dari 15 provinsi yang dilakukan RAAB yang sudah memiliki Komite Mata Daerah yang dibentuk berdasarkan Surat Keputusan (SK) Gubernur. Hal ini merupakan salah satu komitmen pemerintah provinsi Bali dalam penanggulanan gangguan penglihatan dan kebutaan dari segi tata kelola pemerintahan. Provinsi lain di Indonesia yang juga sudah membentuk Komatda yaitu Provinsi Jawa Barat, Jawa Timur, Jawa Tengah. Provinsi Sumatera Selatan dan Maluku yang merupakan provinsi dengan angka kebutaan lebih tinggi dibandingkan Bali hingga saat ini belum memiliki Komite Mata Daerah.

Indikator dari sumber daya manusia pada 6 building blocks adalah distribusi sumber daya manusia bidang kesehatan mata yang professional sesuai dengan jumlah penduduk. Sumber daya manusia di bidang kesehatan mata mencangkup Dokter Spesialis Mata, perawat mahir, refraksionis terlatih, perawat kesehatan mata masyarakat dan kader kesehatan mata terlatih. Distribusi Dokter Spesialis Mata diharapkan sesuai dengan kebutuhan berdasarkan jumlah penduduk dan akses layanan kesehatan, ketersediaan perawat mahir mata di daerah dan setiap puskesmas memiliki minimal satu perawat kesehatan mata masyarakat. $^{3}$

Distribusi dari sumber daya manusia yang professional harusnya sesuai dengan jumlah penduduk. ${ }^{3}$ Seorang dokter spesialis mata, perawat mahir terlatih dan 
refraksionis terlatih idealnya melayani 250.000 populasi. ${ }^{7}$ Data jumlah populasi di provinsi Bali adalah 4.336,9 juta jiwa, dengan demikian diharapkan jumlah dokter spesialis mata, perawat mahir terlatih dan refraksionis terlatih adalah masing-masing 17 orang. Jumlah Dokter mata di Bali saat ini adalah 73 dan sudah berlebih dari yang diharapkan. Jumlah Dokter spesialis mata di Bali juga lebih banyak dibandingkan dengan data di Provinsi Sulawesi Selatan pada tahun 2015, dengan jumlah penduduk 8.372 juta jiwa dan dokter spesialis mata sebanyak 67 orang. ${ }^{8}$ Meskipun banyak dokter spesialis mata di Bali, namun penyebarannya tidak merata dan berkumpul di kota besar. Distribusi penyebaran dokter spesialis mata di kota dan kabupaten perlu dilakukan untuk menurunkan angka kebutaan dan gangguan penglihatan.

Jumlah refraksionis di Bali saat ini masih kurang dibandingkan jumlah yang dibutuhkan. Dibandingkan dengan kondisi di Kota Pariaman, sebuah kota di Provinsi Sumatera Barat, yang sudah memiliki tenaga refraksionis di Puskesmas, tenaga refraksionis di Bali masih terpusat di pelayanan kesehatan level sekunder dan tersier. ${ }^{9}$ Seorang perawat kesehatan masyarakat idealnya melayani 30.000 populasi dan seorang kader kesehatan mata terlatih melayani 5.000 populasi, sehingga di Provinsi Bali seharusnya memiliki minimal 143 perawat kesehatan mata terlatih dan 860 orang kader. Propinsi Jawa Barat, pada level primer sudah memiliki program kesehatan mata dengan kader terlatih terhadap kesehatan mata sebanyak 480 orang. ${ }^{10}$ Puskesmas di provinsi Bali hanya memiliki pemegang program mata yang bekerja multiprogram. Hal ini dapat menyebabkan tidak terlaksananya program mata dengan maksimal karena banyaknya program lain yang juga perlu dilaksanakan.

Indikator dari akses pelayanan kesehatan adalah Cataract Surgical Rate (CSR) dan Cataract Surgical Coverage (CSC). Berdasarkan Peraturan Menteri Kesehatan Republik Indonesia Nomor 29 tahun 2016 tentang Penyelenggaraan Pelayanan Kesehatan Mata di Fasilitas Pelayanan Kesehatan, jenis dan bentuk pelayanan dibagi menjadi pelayanan kesehatan mata primer, sekunder dan tersier. ${ }^{11}$ Besarnya nilai CSR dan CSC merupakan hasil dari upaya yang dilakukan dari tingkat pelayanan primer sampai dengan tersier. Deteksi dini gangguan penglihatan di tingkat Posbindu, identifikasi gangguan penglihatan terutama katarak di puskesmas, operasi katarak di RS Kabupaten/Kota, pelayanan kelainan refraksi berbasis sekolah, penyediaan layanan rehabilitasi bagi penderita gangguan penglihatan kebutaan permanen memegang peranan penting untuk mencapai CSR yang diharapkan.

Angka CSR di Bali mengalami peningkatan dari tahun 2015 sejumlah 808, pada tahun 2016 menjadi 1485, tahun 2017 sejumlah 1601 dan 1746 pada tahun 2018. ${ }^{12}$ Angka CSR provinsi Bali pada tahun 2019 adalah 1.896. Kegiatan deteksi dini gangguan penglihatan di Posbindu di provinsi Bali hingga saat ini belum terlaksana. Dari hasil wawancara kepada pemegang program puskesmas, kegiatan skrining yang dilakukan pada saat Posbindu adalah skrining untuk hipertensi, diabetes dan kolesterol. Identifikasi gangguan penglihatan di Puskesmas dilakukan oleh Dokter Umum, dan bila ditemukan katarak maka dirujuk ke RS tipe C/B. Sedangkan untuk pelayanan refraksi, Puskesmas rutin melakukan skrining kelainan refraksi di sekolah-sekolah dan apabila ditemukan kelainan refraksi maka dirujuk ke RS/ dokter spesialis untuk mendapatkan kacamata. WHO menyatakan bahwa pelayanan kesehatan mata di pusat pelayanan kesehatan primer di Indonesia masih kurang. ${ }^{13}$

Provinsi Bali telah mengalokasikan anggaran untuk Program PGP dari dana BOK. Sebagian besar masyarakat di Provinsi Bali juga telah terjangkau oleh sistem JKN yaitu BPJS, hal ini dapat dilihat dari banyaknya pasien yang dirujuk menggunakan BPJS dari pusat pelayanan primer. Pelayanan kesehatan mata sebagai upaya penanggulangan kebutaan dan gangguan penglihatan ditanggung oelh BPJS. ${ }^{14}$ Sumber pendanaan alternatif juga didapatkan dari beberapa NGO dan organisasi lainnya yang berperan serta aktif untuk mendanai kegiatan operasi katarak massal.

Sistem pembiayaan kesehatan yang ideal adalah sistem yang memiliki dana yang memadai untuk memebrikan akses dan pemanfaatan layanan kesehatan yang adil tanpa beban pembayaran apapun kepada pasien..$^{15}$ Data mengenai status pelayanan kesehatan mata di 11 negara Asia Tenggara, yaitu Bangladesh, Bhutan, India, Indonesia, Maldives, Myanmar, Nepal, Sri Lanka, Thailand dan Timor Leste pada tahun 2015 menunjukkan bahwa asuransi untuk perawatan kesehatan mata belum terdistribusi secara merata. ${ }^{16}$ Myanmar dan Bhutan tidak memiliki skema asuransi kesehatan umum. Sri Lanka dan Timor Leste menyediakan pelayanan kesehatan gratis temasuk pelayanan kesehatan mata. ${ }^{17,18}$ Pemerintah Maladewa mengasuransikan semua orang di negaranya. Seluruh pelayanan kesehatan termasuk pelayanan kesehatan mata di Maladewa ditanggung oleh "Aasandha", sebuah skema asuransi sosial pemerintah. Selain pelayanan medis dan operasi, pemerintah Maladewa juga menawarkan 65 US Dollar untuk kacamata dengan batas waktu 2 tahun. Indonesia dan Thailand memiliki sistem asuransi jaminan kesehatan untuk pelayanan mata, namun untuk mengakses perawatan kesehatan mata gratis tersebut masih ada beban pembayaran (out of pocket) yang harus dikeluarkan oleh pasien. ${ }^{16}$

Ketersedian obat-obatan, bahan habis pakai dan alat medis yang memadai dan berkelanjutan dan pemanfaatan serta pengambangan teknologi yang tepat guna merupakan salah satu upaya untuk mencapai pelayanan kesehatan mata yang baik. Puskemas memiliki beberapa jenis alat untuk melakukan pelayanan kesehatan mata namun belum dapat dimanfaatkan dengan baik oleh sumber daya manusia yang ada, sehingga belum tepat guna. Standarisasi diperlukan untuk dijadikan acuan pengadaan obat-obatan, bahan habis pakai dan alat medis sehingga pelayanan kesehatan mata dapat dilakukan dengan baik.

Sistem rujukan gangguan penglihatan dilaksanakan berjenjang dimulai dari Posbindu, Fasilitas Kesehatan Tingkat Pertama (FKTP) dan Fasilitas Kesehatan Rujukan Tingkat Lanjutan yang meliputi Rumah Sakit Sekunder dan Tersier, termasuk Rumah Sakit Khusus Mata. Sejalan dengan peerwujudan Indonesia 
Sehat, maka dilaksanakan upaya pengintegrasian pelayanan kesehatan penglihatan mata dengan Jaminan Kesehatan Nasional (JKN). ${ }^{19}$

Sistem Informasi Penganggula- ngan Gangguan Penglihatan Nasional yang disingkat "SIGALIH" merupakan suatu sistem informasi yang dikembangkan untuk mempermudah alur pencatatan dan pelaporan rujukan, sehingga rujukan gangguan penglihatan dapat dilaksanakan dengan efektif. SIGALIH telah diresmikan oleh Menteri Kesehatan Republik Indonesua pada peringatan Hari Penglihatan Sedunia Tahun 2018. Sistemini berbasis web atau android yang merupakan sisten informasi bagi Kementererian Kesehatan, Dinas Kesehatan, Rumah Sakit, Puskesmas sampai dengan Posbindu untuk mengumpulkan, menyimpan dan menganalisa data penduduk yang mengalami gangguan penglihatan khususnya katarak yang bertujuan untuk menurunkan angka kebutaan. SIGALIH berfungsi sebagai media komunikasi dan informasi yang selalu update antara Pusbindu, Puskesmas dan Rumah Sakit untuk bisa memberikan informasi yang dibutuhkan agar penanganan pasien lebih cepat, efektif dan efisien. ${ }^{20}$ Berdasarkan hasil wawancara yang dilakukan ke Puskesmas dan dokter Spesialis Mata, pencatatan hasil skrining dan gangguan mata pada pasien masih secara manual. Penggunaan aplikasi SIGALIH ini belum dilakukan bahkan dari pihak puskesmas tidak mengetahui adanya sistem tersebut. Hal ini dapat dikarenakan sosialisasi yang kurang mengenai sistem aplikasi tersebut.

Kemitraan bertujuan untuk memfasilitasi Kerjasama dan koordinasi antar instansi pemerintah dan NGO. Indikator dari kemitraan ini adalah surat keputusan bersama (SKB) antar instansi pemerintah yang terkait dan Forum Komunikasi para stake holder Program Penanggulangan Gangguan Penglihatan. Beberapa NGO yang ada di Indonesia adalah Helen Keler International, Christoper Blinden Mission, Fred Hollows, Lions International.

Provinsi Bali menjalin kemitraan dengan PERDAMI Bali dan JFF dalam upaya penanggulangan gangguan penglihatan dan kebutaan. PERDAMI Bali sebagai organisasi profesi berperan dalam menyumbangkan pikiran dan tenaga serta upaya terbaiknya dalam membantu pemerintah. Melalui para anggotanya, anggotanya yaitu dokter spesialis mata, PERDAMI akan selalu berdampingan dengan pemerintah dan para stakeholder Penanggulangan Gangguan Penglihatan lainnya dalam memberikan kajian akademis, inisiasi implementasi program dan upaya-upaya strategis lainnya dalam membantu masyakatak terbebas dari gangguan penglihatan dan kebutaan. Anggota PERDAMI Bali aktif berkontribusi dalam pelaksaan program PGPK yang dilaksanakan oleh RS Mata Bali Mandara dan juga oleh JFF. PERDAMI Bali juga bekerja sama dengan Program Studi Spesialis Ilmi Kesehatan Mata Universitas Udayana, dimana residen yang sedang menempuh pendidikan juga masuk menjadi anggota muda PERDAMI.

\section{SIMPULAN}

Pelayanan kesehatan mata di provinsi Bali sudah terlaksana, namun belum ideal. Puskesmas sebagai fasilitas kesehatan primer, memiliki peran penting dalam melakukan pelayanan kesehatan mata untuk mengatasi masalah gangguan penglihatan dan kebutaan, namun hingga saat ini pelayanan kesehatan mata belum menjadi prioritas pelayanan. Sumber daya manusia dan juga sarana prasarana yang tersedia di fasilitas kesehatan tingkat pertama masih kurang dari yang dibutuhkan sehingga deteksi dini kasus gangguan penglihatan dan kebutaan belum terlaksana dengan baik.

Hal-hal yang dapat dilakukan untuk meningkatkan pelayanan kesehatan mata dan meningkatkan CSR di Bali adalah dengan meningkatkan penyebaran dokter spesialis mata ke kabupaten, meningkatkan jumlah dan kemampuan kader dengan melakukan pelatihan kader mata di tingkat puskesmas dan di tingkat desa secara berkala, edukasi terhadap kebutaan dan gangguan penglihatan yang bisa dicegah harus terus dilakukan secara berkala, serta sebaiknya pemegang program mata di tingkat provinsi dan puskesmas dipegang oleh satu orang pemegang program adalah orang yang tetap agar program yang ada dapat berjalan secara berkesinambungan.

\section{KONFLIK KEPENTINGAN}

Penulis menyatakan tidak terdapat konflik kepentinga terkait publikasi dari artikel penelitian ini.

\section{ETIKA DALAM PUBLIKASI}

Penelitian ini bersifat pengumpulan data dan juga wawancara, seluruh subjek yang dilakukan wawancara telah menandatangani lembar informed consent terkait pengumpulan data, kemudian dalam penelitian ini kaji etik tidak bersifat mandatorik.

\section{PENDANAAN}

Penulis tidak mendapat tambahan dana dari pemerintah ataupun sekotr swasta lainya dalam pelaksaanaan dari penelitian ini.

\section{KONTRIBUSI PENULIS}

Seluruh penulis telah berkontribusi terhadap penyusunan dari artikel ini dan setuju terhadap versi final untuk dilakukan publikasi.

\section{DAFTAR PUSTAKA}

1. Kementrian Kesehatan RI. Situasi dan gangguan penglihatan dan kebutaan. Pusat data dan Informasi Kesehatan RI. Jakarta; 2014.

2. Foster A, Gilbert C, Johnson G. Changing patterns in global blindness: 1988-2008. Community Eye Health. 2008;21(67):37-9.

3. Kementerian Kesehatan RI. Peta Jalan Penanggulangan gangguan penglihatan di Indonesia Tahun 2017-2030. Direktorat Jenderal Pencegahan dan Pengendalian Penyakit. Jakarta; 2019.

4. World Health Organization. Universal eye health: a global action plan 2014-2019; 2013.

5. Departemen Kesehatan RI. Indonesia Lakukan Bilateral Meeting dengan International Agency for the Prevention of Blindness; 2019.

6. Kementerian Kesehatan Republik Indonesia. Peraturan Menteri Kesehatan Republik Indonesia Nomor 29 Tahun 2016 Tentang Penyelenggaraan Pelayanan Kesehatan Mata di Fasilitas Pelayanan Kesehatan. Kementerian Kesehatan Republik Indonesia. Jakarta; 2016.

7. Kementerian Kesehatan RI. Indonesia Mencapai Universal Eye Health. Direktorat Jenderal Pencegahan dan Pengendalian Penyakit. Jakarta; 2018.

8. Amalius AA. Situational Analysis of Eye Care Services in South Sulawesi. Ophthalmologica Indonesiana. 2016;42(3):1-5.

9. Marwis A, Firdawati K, Erkadius B. Analisis Sistem Rujukan Kelainan Refraksi dari Puskesmas ke Rumah Sakit di Kota Pariaman 
Tahun 2018. Jurnal Kesehatan Andalas. 2018;8:3-7.

10. Laksana EP, Rini M. Proses Pembuatan Plan of Action dari Eye Care. Pusat Mata Nasional Rumah Sakit Mata Cicendo. Bandung; 2020.

11. Kementerian Kesehatan Republik Indonesia. Keputusan Menteri Kesehatan Republik Indonesia nomor HK.02.02/Menkes/291/2016 tentang Komite Mata Nasional untuk Penanggulangan Gangguan Penglihatan dan Kebutaan. Jakarta; 2016.

12. PERDAMI. Who vision 2020; 2017.

13. World Health Organization. Situation Analysis of VISION 2020 in the WHO South-East Asia Region; 2012.

14. BPJS Kesehatan. Transformasi BPJS Kesehatan Center Menjadi Layanan PIPP. (Edisi 62 thaun 2018); 2018.

15. Sukati VN, Moodley VR, Mashige KP. A situational analysis of eye care services in
Swaziland. J Public Health Afr. 2018;9(3):892. doi: 10.4081/jphia.2018.892.

16. Das $\mathrm{T}$, Ackland $\mathrm{P}$, Correia $\mathrm{M}$, Hanutsaha $\mathrm{P}$, Mahipala P, Nukella PB, Pokharel GP, Raihan A, Rao GN, Ravilla TD, Sapkota YD, Simanjuntak G, Tenzin N, Thoufeeq U, Win T; IAPB South East Asia Region Eye Health Study Group. Is the 2015 eye care service delivery profile in Southeast Asia closer to universal eye health need! Int Ophthalmol. 2018;38(2):469-480. doi: 10.1007/s10792-017-0481-y.

17. Ramke J, Palagyi A, Naduvilath $T$, du Toit R, Brian G. Prevalence and causes of blindness and low vision in Timor-Leste. $\mathrm{Br} \mathrm{J}$ Ophthalmol. 2007;91(9):1117-21. doi: 10.1136/ bjo.2006.106559.

18. Edussuriya K, Sennanayake S, Senaratne T, Marshall D, Sullivan T, Selva D, Casson RJ. The prevalence and causes of visual impairment in central Sri Lanka the Kandy Eye study. Ophthalmology. 2009;116(1):52-6. doi: 10.1016/j.ophtha.2008.08.034.

19. Cakrawati L. Strategic Plan of Eye Care in Indonesia. Perpustakaan Cicendo. Bandung; 2019.

20. Kementrian Kesehatan Republik Indonesia. Sigalih Aplikasi berbasis Web/Android Untuk Deteksi Dini Gangguan Penglihatan di Posbindu; 2018.

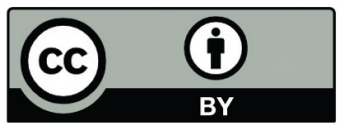

This work is licensed under a Creative Commons Attribution 